\title{
Sensitivity of sunfish (Lepomis gibbosus) to qualitative changes in reinforcement
}

\author{
VICTOR M. ASHE and DAVID CHISZAR \\ University of Colorado, Boulder, Colorado 80309
}

\begin{abstract}
Shifts in reward magnitude have often failed to produce rapid performance changes in the instrumental behavior (swimming speed) of fish. The present within-subjects experiment was conducted to determine if sunfish (Lepomis gibbosus) are sensitive to qualitative shifts in reinforcement. Shifts from pellet to mealworm (Tenebrio molitor) reinforcement produced large increases in straight-alley swimming speed, and a shift from mealworm to pellet reinforcement produced an equally large performance decrement. These results show that sunfish were sensitive to this qualitative shift in reinforcement. A shift-saliency hypothesis is advanced to account for the seemingly disparate reports in the literature.
\end{abstract}

Lowes and Bitterman (1967) reported that fish trained with 40 Tubifex worms as the reinforcer and shifted to four worms showed no performance decrement, and that the performance of fish shifted from 4 to 40 worms gradually converged upon the performance of the 40-worm control group. More recently, Mackintosh (1971) reported that fish shifted from five pellets to one pellet in a similar task did not differ reliably from the control groups (one to one and five to five). On the basis of these and similar data, Mackintosh (1971) concluded that, compared to rats, fish are "relatively insensitive to changes in the conditions of reinforcement" (p. 231). While some reward magnitude experiments support Mackintosh's conclusion, there is no evidence that fish are insensitive to qualitative changes in reinforcement. Accordingly, the present experiment was designed to determine what effects, if any, qualitative shifts in reinforcement have on performance.

\section{METHOD \\ Subjects \\ The subjects were six locally seined sunfish, Lepomis gibbosus, $8-12 \mathrm{~cm}$ long. The fish were housed individually in 57 -liter aquaria for 20 days prior to pretraining and were fed to satiation daily on 50-mg herring-meal pellets provided by the State of Colorado, Department of Game, Fish, and Parks (mean number consumed/fish/day $=3$ ).}

Apparatus.

The apparatus was a straight alley constructed of clear Plexiglas $(6.25 \mathrm{~mm}$ thick) and measured $152.5 \mathrm{~cm}$ long, $24.3 \mathrm{~cm}$ deep, and $16.6 \mathrm{~cm}$ wide. The ends of the alley were partitioned into $25-\mathrm{cm}$-long chambers by guillotine doors. One chamber served as the startbox, the other served as the goalbox. The alley was completely filled with water and was provided with a filter and an airstone (both located in the goalbox).

The city of Boulder, Colorado, granted permission for the capture of fish employed in this study. Requests for reprints should be sent to D. Chiszar, Department of Psychology, University of Colorado, Boulder, Colorado 80309. This paper is sponsored by David R. Thomas, who takes full editorial responsibility for its contents. The study was supported in part by the Marjorie Mosher Schmidt Foundation.

\section{Procedure}

Pretraining consisted of free exploration of the apparatus with pellet-baited goalbox for $5 \mathrm{~min} / \mathrm{day}$ for 3 consecutive days. Feeding in the home aquaria ceased $24 \mathrm{~h}$ prior to pretraining; all subsequent feeding took the form of reinforcement in the straight alley. All reinforcers were placed in the rear of the goalbox, behind the filter and aerator. Hence, subjects could not see the food until they entered the goalbox.

Training began $24 \mathrm{~h}$ after the third exploration period. Subjects were placed in the startbox and the guillotine doors were opened $10 \mathrm{sec}$ later. The time elapsing between exit from the startbox and entry into the goalbox was measured with a .1-sec stopwatch. Training was distributed over four phases in a withinsubjects design. Phase I consisted of 18 days of training, with a single pellet as the reinforcer on each of two daily trials. The intertrial interval consisted of a 50 -sec goalbox confinement plus a 10-sec pretrial startbox confinement. Subjects were transferred via dip net. Phase II consisted of 15 days of mealworm reinforcement (larvae of Tenebrio molitor) with one-half of a mealworm $(50$ to $70 \mathrm{mg}$ ) given on each of the two daily trials. Phase III consisted of 27 days of pellet reinforcement as in Phase I. In Phase IV, four subjects were shifted to mealworm reinforcement for the 43-day duration of the study; one subject was left on pellet reinforcement for the first 16 days and then shifted to mealworm reinforcement for the remaining 27 days. The sixth subject was shifted to oligocheate reinforcement (as a pilot for another experiment) and will not be considered further. Subjects were given two trials/day on the first 9 days of Phase IV and one trial/day on the remaining 34 days with whole mealworm reinforcement.

\section{RESULTS}

Latencies were transformed into reciprocals, partitioned into two-trial blocks, and subjected to analysis of variance. As can be seen in Figure 1, there is some improvement in performance in Phase I $(F=2.19$, $\mathrm{df}=17 / 85, \mathrm{p}<.05)$, and dramatic improvement with the shift to mealworm reinforcement in Phase II $(F=8.47, \mathrm{df}=14 / 70, \mathrm{p}<.01)$. The mealworm-to-pellet shift in Phase III produced a marked decline in performance $(F=2.84, \mathrm{df}=41 / 205, \mathrm{p}<.01)$. The shift to mealworm reinforcement in Phase IV produced an increase in performance similar to that seen in Phase II $(F=4.95, \mathrm{df}=25 / 75, \mathrm{p}<.01)$. 


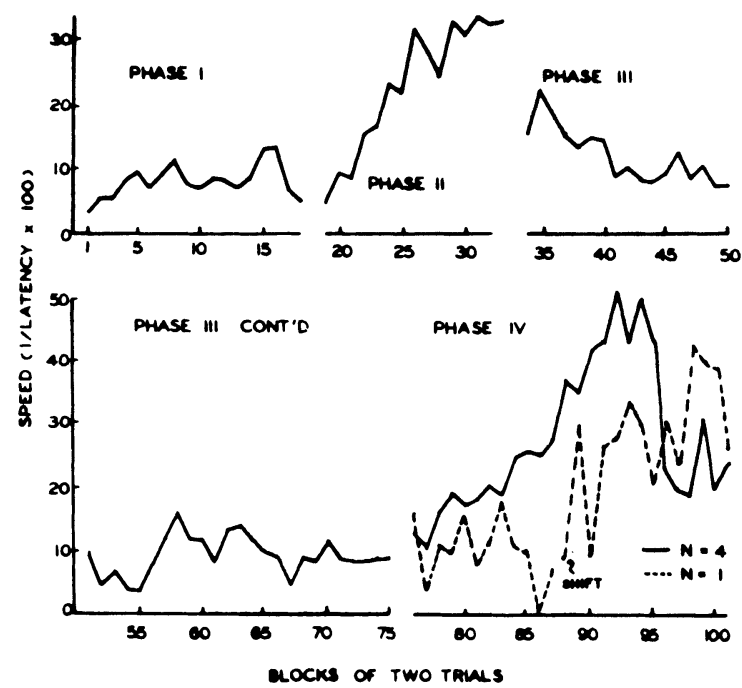

Figure 1. Swimming speed $(1 /$ latency $\times 100)$ is plotted across blocks of two trials. Points connected by solid line in Phases I, II, and III represent the average speed of all six subjects. As noted in the text, four subjects were shifted to mealworms on Block 76 (solid line, Phase IV); one subject remained on pellet reinforcement up to Block 87 , and was then shifted to mealworm reinforcement (broken line, Phase IV).

Comparison of the last five blocks of the two pellet phases (I and III) established the equivalence of performance with pellet reinforcement $(F<1)$. A similar test of the two mealworm phases also yielded $\mathrm{F}<1$. A comparison of the mean speed over the last five blocks of the two mealworm phases with the mean speed over the last five blocks of the two pellet phases showed that terminal performance with mealworm reinforcement differed reliably from that obtained with pellet reinforcement $(\mathrm{F}=23.38, \mathrm{df}=1 / 5, \mathrm{p}<.01)$.

The subject maintained on pellet reinforcement after four others were shifted to mealworms in Phase IV provides a between-groups control for the pellet-tomealworm shift. A sign test shows that this subject's performance was below that of the shifted animals during the first 12 blocks of Phase IV $(p=.01)$. When finally shifted to mealworms, performance improved to the level of the other four animals $(p>.10)$. These sign tests corroborate the graphic representation of this subject's data in Figure 1 (broken line).

\section{DISCUSSION}

The qualitative shifts from pellet to mealworm reinforcement produced large increments in swimming speed; the shift from mealworms to pellets likewise produced a large performance decrement. Clearly, sunfish are sensitive to qualitative changes in conditions of reinforcement. Mackintosh's (1971) failure to obtain reliable performance decrement with goldfish shifted from five to one pellet(s) may be attributable to the relative indiscriminability of shifts in the magnitude of pellet reinforcement. As a working hypothesis, shifts might be made more salient in at least two ways: (a) shift from a less palatable reinforcer to a more palatable one and/or vice versa, and (b) shift the magnitude of a very palatable reinforcer. The present experiment is an example of the former. An example of the latter was provided by Raymond, Aderman, and Wolach (1972). These investigators conducted a between-subjects experiment with goldfish in a straight alley; reinforcement magnitude was varied by using $2 \times 2 \mathrm{~cm}$ cubes of freeze-dried worms in the large-magnitude condition (L) and $.2 \times .2 \mathrm{~cm}$ cubes in the small-magnitude condition (S). The L-S shift produced a reliable decline in performance to the level of the S-S control group, while the S-L shift produced a reliable improvement in performance to the level of the L-L control group.

Under the assumption that live or dried larvae and worms are more palatable than pellets, the failure of Lowes and Bitterman (1967) to obtain performance decrement in their L-S condition with Tubifex worms seems incompatible with the shift-saliency hypothesis advanced above. But, as Raymond et al. (1972) point out, the Lowes and Bitterman experiment may not be comparable to the others owing to the different task (i.e., target striking as opposed to swimming the length of an alley). This argument has merit to the extent that the latency measures obtained in straight-alley experiments are more sensitive to changes in response vigor than the measure obtained in the target-striking task.

It seems reasonable to conclude that fish are sensitive to both qualitative and quantitative changes in conditions of reinforcement, provided that the changes are sufficiently salient and that the dependent variables are sufficiently sensitive. This implies that fish exhibit incentive learning processes that are comparable to those of higher vertebrates and that theories concerning incentive effects and their retention in higher vertebrates (e.g., Logan \& Wagner, 1965; Spear, 1967) may also be applicable to the instrumental behavior of fish.

\section{REFERENCES}

Logan, F. A., \& WAgner, A. R. Reward and punishment. Boston: Allyn \& Bacon, 1965.

Lowes, G., \& Bitterman, M. E. Reward and learning in the gold fish. Science, 1967, 157, 455-457.

Mackintosh, N. J. Reward and aftereffects of reward in the learning of goldfish. Journal of Comparative and Physiological Psychology, 1971, 76, 225-232.

Raymond, B., Aderman, M., \& Wolach, A. H. Incentive shifts in the goldfish. Journal of Comparative and Physiological Psychology, 1972, 78, 10-13.

SPEAR, N. E. Retention of reinforcer magnitude. Psychological Review, 1967, 74, 216-234.

(Received for publication March 21, 1976.) 